https://doi.org/10.52449/1857-4114.2020.36-2.14

CZU: 796.015.2:615.825-053.6

\title{
EVALUAREA SOMATOSCOPICĂ A COPIILOR DE VÂRSTĂ PREPUBERTARĂ ÎN VEDEREA DETERMINĂRII DEFICIENŢELOR COLOANEI VERTEBRALE
}

\author{
Rîşneac Boris ${ }^{1}$ \\ Racu Sergiu ${ }^{2}$ \\ Constantinescu Mihai ${ }^{3}$ \\ ${ }^{1}$ State University of Physical Education and Sports, Chisinau, Republic of Moldova \\ 2"Stefan cel Mare" University, Suceava, Romania
}

\begin{abstract}
The current situation regarding the state of health, and here we can refer to the functional impairment of the spine of pre-pubertal age children, is superficially approached from the prevention point of view.

Global or partial physical deficiencies, as well as the vicious positions of the body, could be favorably influenced by the use of physical exercises as an associated means of kinesiotherapy.

Currently, the problem of somato-functional growth and development of pre-pubertal children, related to the existing postural hygiene programs, is in a deficient situation, favoring the installation of vicious postural attitudes, which cause complications in the spine such as functional physical deficiencies.
\end{abstract}

Keywords: pre-pubertal, somatoscopic evaluation, functional impairment.

Introduction. The analysis of the specialized literature carried out so far revealed that the frequency of physical deficiencies among school-aged children is very high. Some of the objective causes that trigger and favor the occurrence of physical deficiencies and implicitly the deviation from normal physiological morphological status, can be the following: the most common ones are caused by rickets in childhood, the decreased accuracy of some analyzers; organic diseases; osteoarticular diseases $[3,4$, 8]. In the pre-pubertal and especially puberty age, when growth bone processes are faster, grow more in length and less in thickness, so the height is the one that stands out, and stabilizer muscles are weak, the structural malalignment abnormalities of the locomotor apparatus are more likely to appear. The structure of the skeletal system at this age is in a forming process, the bones are long and thin, the muscular development is low, the joints are in a state of accentuated ligament laxity which favors the lack of stability and implicitly the appearance of the functional physical deficiencies, the vicious posture attitudes, that once installed have an evolutionary trend and are difficult to stabilize or correct.

Besides these structural and functional mismatches, sometimes there are imbalances in the relationships between the segments or even the organs, long and thin arms, pectus carinatum and pectus excavatum, all these being accompanied by functional or psychological disorders.

The dynamics of growth and development during this period, namely the puberty, comes with a complex of specific changes that are not always controlled and hence the appearance of various posture or even functional maladies. Hypotonia can be considered a pathogenic factor of the static and dynamic disorders of the 
locomotor system; this hypotonia generates joint laxity and negatively influences the ability of voluntary control and reflex control of skeletal muscles [5].

Nowadays, the concern regarding somato-functional development and development of pre-pubertal children in relation to existing postural hygiene programs is in a poor condition, favoring the installation of vicious postural attitudes, which causes physical-functional deficiencies of the spine. The most serious segmental deficiencies, the most important in terms of the consequences and complications that can be reached are those of the spine, (kyphosis, lordosis, scoliosis and their combinations).

The purpose of the research is to study aspects of child growth and development during the pre-pubertal period and to highlight vicious bodily attitudes.

The research objectives were to analyze the methodical-scientific literature regarding the prevention of vicious attitudes of the spine; the somatoscopic evaluation of pre-pubertal age children; establishing vicious attitudes and spine definitions.

Methods of research: analysis of specialized literature; pedagogical observation; somatoscopic method; the statisticalmathematical method.

The somatoscopic and anthropometric assessment made for the monitoring of growth and physical development in pre-pubertal age children in order to prevent the occurrence of functional spinal functional deficiencies is mandatory.

The position in which the assessment is carried out is: motionless, with the relaxed shoulders, the upper limbs by the body, the palms at the prono-supine intermediate position, slightly bent fingers, horizontal position of the chin, looking ahead, close heels, peaks at about $45^{\circ}$. [2] In the experiment of selection of the nominated children to perform the experimental programme, it was proceeded to elaborate and implement somatoscopic observation cards, with the purpose of identifying the possible physical attitudes or functional deficiencies of the body posture and especially those of the spine.

In order to do this, a set of front, back and profile human body panels were developed, in which the anthropometric points and markings used in the evaluation process were outlined [6,7]: Picture 1.

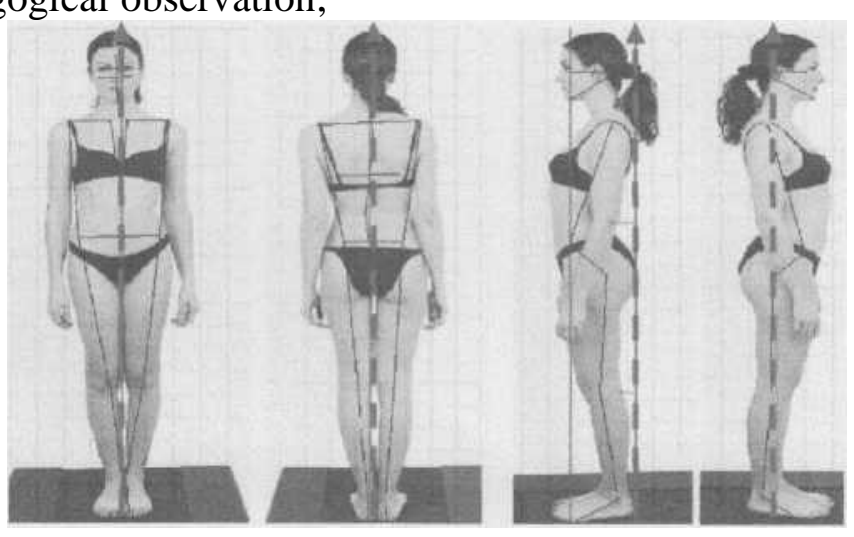

Pic. 1. Pannels, somatoscopic analysis [9]

The implementation of the somatoscopic observation method on an extended sample of 500 pre-pubertal aged pupils (11 to 13 years old), VI and VII class pupils, girls and boys, was one of the important points of our study, together with the questioning of those involved in managing their growth and development process.

The results obtained after carrying out the observations are presented in Table 1. 
Table 1. List with deficiencies found at children aged between 11 to 13 years $(\mathbf{n}=\mathbf{5 0 0})$

\begin{tabular}{|c|c|c|c|c|c|}
\hline $\begin{array}{c}\text { Vicious attitudes } \\
\text { cases discovered }\end{array}$ & $\begin{array}{c}\text { VI class girls } \\
\text { No. of cases of } \\
\text { deficiency } \\
\text { discovered }\end{array}$ & $\begin{array}{c}\text { VII class girls } \\
\text { No. of cases of } \\
\text { deficiency } \\
\text { discovered }\end{array}$ & $\begin{array}{c}\text { VI class boys } \\
\text { No. of cases of } \\
\text { deficiency } \\
\text { discovered }\end{array}$ & $\begin{array}{c}\text { VII class boys } \\
\text { No. of cases of } \\
\text { deficiency } \\
\text { discovered }\end{array}$ & $\begin{array}{c}\text { Total } \\
\text { no./percent of } \\
\text { vicious } \\
\text { attitudes cases } \\
\text { discovered }\end{array}$ \\
\hline Cifotic attitude & 12 & 9 & 7 & 5 & $33-6,6 \%$ \\
\hline Lordosis attitude & 5 & 6 & 6 & 4 & $21-4,2 \%$ \\
\hline Flat back syndrome & 2 & 3 & 7 & 3 & $10-2 \%$ \\
\hline Scoliotic attitude & 14 & 4 & 1 & 2 & $41-8.2 \%$ \\
\hline Cifo-scoliosis attitude & 3 & 34 & 23 & 22 & $115-23 \%$ \\
\hline Total number of cases & 36 & 4 & 7 & 3 \\
\hline
\end{tabular}

The data obtained from the scientific study carried out on postural deficiencies found, indicate that out of the total number of subjects observed (500), 115 develop a vicious postural attitude of the spine, which represents $23 \%$ - practically one in five children develops a vicious postural attitude.

Of the total number of vicious attitudes cases discovered, the scoliotic ones are highlighted by $8,2 \%$ and the cifotic ones by $6,6 \%$, exceeding the percentage of $50 \%$ of all the cases of deficiency found. As a deficient attitude, lordosis is represented by $4,2 \%$ and the flat back syndrome and cifo-scoliosis by $2 \%$ each. Scoliosis is by far the most common type of vicious postural attitude of the spine, followed by kyphosis and their combinations. We will specify that the large number of scoliotic attitudes found - 41, representing 8,2\% of the observed subjects, is alarmingly high because a scoliosis at this age is almost impossible to be managed, once installed, it has an accelerated evolutionary trend due to the physiological changes that the body is developing at this age. In the same context, we will specify that the functional spinal deficiencies installed at this age, being evolutionary, cannot be corrected by classical methods; therefore the prophylactic method is the best approach.

The fact that, after carrying out some somatoscopic observations there is a $23 \%$ (out of a total of 500 observations) of children aged 11 to 13 years who develop vicious postural attitudes of the spine, requires a scientific approach of the phenomenon, as the complications that can arise with these posture deficiencies can affect and damage the growth and development process during this period.

Results. The implementation of the somatoscopic observation method on an extended sample of 500 pre-pubertal aged pupils (11 to 13 years old), represented one of the important points of the scientific study.

The data obtained from the scientific study carried out on postural deficiencies found, indicate that out of the total number of subjects observed (500), 115 develop a vicious postural attitude of the spine, which represents $23 \%$ - practically one in five children develops a vicious postural attitude.

Conclusions. Based on the study, a somatoscopic evaluation mechanism has been developed which has been transposed into a quantifiable measuring instrument, ensuring a degree of increased objectivity. As a result of 
the evaluation, a sample group of children was established, that later underwent a programme of physical regeneration and recovery of the body posture.

\section{References:}

1. Birtolon SS.A. (1978). Physical exercises and the spine. Bucharest: Sport-Turism. p. 27.

2. Cordun M. (1999). Medical kinetology. Bucharest: Publ. House: Axa, p. 59-63.

3. Dragan I. (1981). Medical physical culture. Bucharest: Publ. House "Sport Turism", p. 47.

4. Jianu M. (2010). Pediatric scoliosis. Bucharest: Publ. House "Proeditură şi Tipografie", p. 34.

5. Mark V. (1983). Massage and kinetotherapy. Bucharest: Publ. House "Sport Turism", p. 106.

6. Mark V., Pâncotan V. (2005). The evaluation of patients in degenerative rheumatoid diseases of the spine. Oradea: Publ. House Universităţii, p.23.

7. Sidenco L.E. (2005). Practical guide to articular and muscular evaluation in physical therapy. Bucharest: Publ. House Editura Fundaţiei "România de Mâine", p. 26.

8. Zaharia C. (1980). Scoliosis. Bucharest: Publ. House "Editura Medicală", p. 20.

9. http://www.ortodonziabologna.com, Used instruments - Orthodontics Bologna, (visited on $13^{\text {th }}$ of August 2020).

\section{Editura USEFS}

Str. A. Doga 22, Chișinău, Republica Moldova

Tel.: 022311241

revistausefs@mail.ru 